\title{
The role of effective lever length in the perception of lifted weights*
}

\author{
CHRISTOPHER M. DAVIS \\ Simon Fraser University, Burnaby, British Columbia, Canada
}

\begin{abstract}
Objects are lifted through a system of body levers and, since the force required to lift objects decreases as the effective lever length is shortened, it was hypothesized that the perceived heaviness of objects would be less when they were lifted with the elbow bent than with it extended. Cans lifted from greater initial angles were consistently judged to be lighter by blindfolded Ss.
\end{abstract}

The motor theory of comparative weight judgment held that when two objects are serially hoisted for the purpose of judging their heaviness, the comparison was between the ease with which the objects could be lifted (Müller \& Schumann, 1889). Accordingly, the same muscular force required to lift the first object is applied to the second object. If the second object comes up easily, it is judged to be lighter than the first; if it comes up with difficulty, it is judged to be heavier. It follows that if the comparative judgment is based on the relative ease of lifting, then any condition which makes one object easier to lift than another would cause it to be judged to be lighter. One such condition is the mechanical properties of the lifting system. Objects are lifted through a system of levers comprising the bones and muscles of the hand and arm, so that the mechanical properties of that system may affect the ease with which objects can be lifted.

Davis (1973) found that by altering the mechanical advantage of the arm-hand system, the size-weight illusion could be significantly reduced and sometimes reversed. In that experiment, the lever arm was altered by placing the objects either on the fingertips or near the base of the fingers. But the length of the lever arm is varied only slightly in human experience. Objects are lifted by the hands or kicked by the feet repeatedly in much the same way, so the levers are nearly uniform. However, the effective lever length, or moment arm of force, is easily and often changed, and those changes may affect weight perception. For example, it requires less force to lift an object by elbow flexion beginning with the arm bent than with it extended, because the effective leng th of the lever is the perpendicular distance from a line of force to an axis through the fulcrum (O'Connell \& Gardner, 1972). In the example, since the force is gravity, the vertical line through the center of mass of the object lifted is the line of force and the elbow joint is the fulcrum. Figure 1 demonstrates the decreasing moment arm of force (B and $\left.B^{\prime}\right)$ as the elbow is flexed to $60 \mathrm{deg}$ from horizontal. In this particular

*This research was supported by NRC of Canada Grant A8611 to the author. Requests for reprints should be sent to the author, Department of Psychology, Simon Fraser University, Burnaby, B.C., Canada. arrangement, the effective lever length is equal to the cosine of the angle the forearm makes with respect to the horizontal, so that when the elbow is at an angle of $60 \mathrm{deg}$, the effective lever is exactly half the length of the lever arm, so that the force required to lift the object is less. ${ }^{1}$

The following experiment is an attempt to transfer this lifting lever situation to the psychological laboratory for the purpose of determining the effect of varying effective lever length on the perceived relative heaviness of objects.

\section{METHOD}

Subjects

Ss were 32 right-handed university student volunteers.

\section{Apparatus}

The right arm of a padded upright chair was hinged near the rear so that it could be raised at the front and held at an angle of

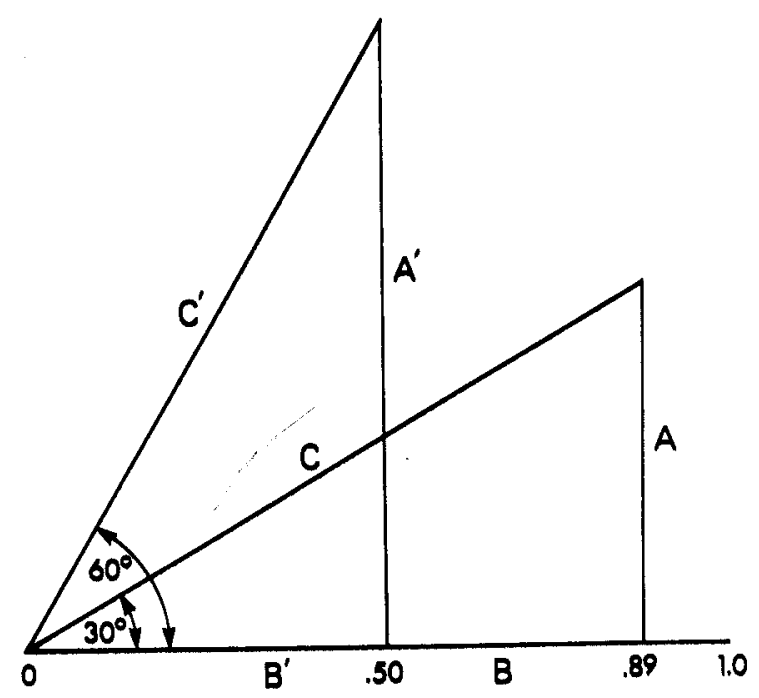

Fig. 1. The geometric analysis of effective lever length when hand-held objects are lifted by elbow flexion. The full extent of the horizontal Line $C$ and Line $C^{\prime}$ are the lever arm, in this case the forearm, and are of course equal. The horizontal line and Line Segments B and B' represent the eff ective lever length, or moment arm of force, when an object is supported from increasingly acute initial angles. 


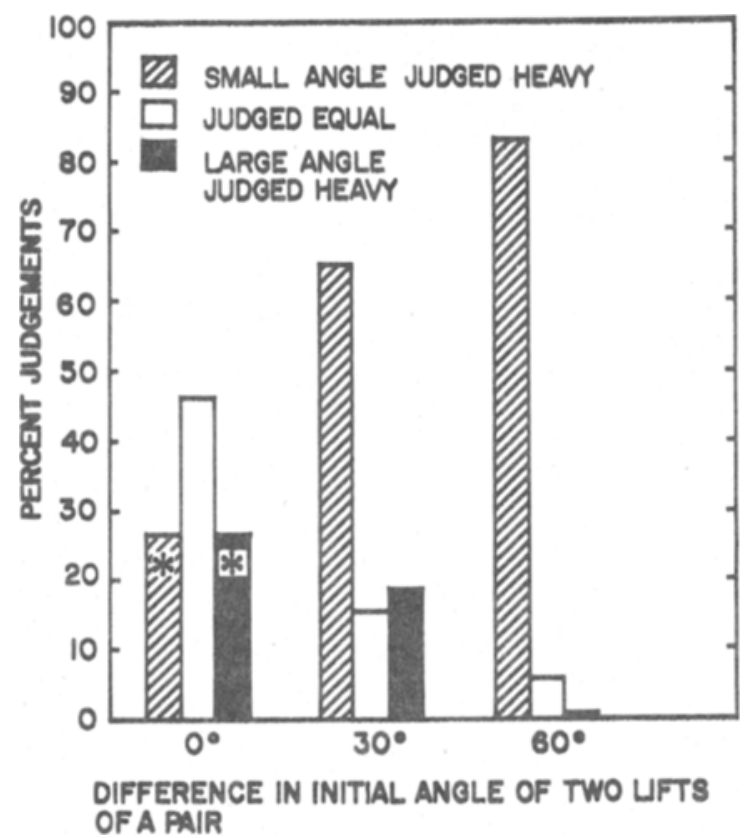

Fig. 2. The difference judgments as a function of difference in initial angle.

30 or 60 deg between its normal horizontal and its elevated positions. A rectangular brace of aluminum, $7 \times 55 \mathrm{~cm}, 2 \mathrm{~mm}$ thick, through which a series of holes, $7 \mathrm{~mm}$ in diam and $1 \mathrm{~cm}$ apart, had been drilled along the center of the long dimension, was taped to the dorsal surface of S's forearm so that the one end of the aluminum was at S's elbow. The other end of the brace extended under and beyond the volar surface of the outstretched hand, so that the series of holes was visible between the third and fourth fingers. A wire hook inserted in to the center of a 2.5-cm-diam wood dowel (a sort of miniature hay baling hook) was threaded through the proximal visible hole so that the dowel rested across the base of the palmar surface of the four fingers. With the brace taped on the S's arm resting on the elevation platform, the hood extended below and beyond the platform so that objects could be hung from the hook. S's arm was placed on the elevation platform with the elbow even with the hinged end of the platform and with the brace resting on it.

The lifted objects were six 1-qt cans, two of which weighed $400 \mathrm{~g}$, two, $550 \mathrm{~g}$, and two, $700 \mathrm{~g}$. The cans were painted white and were identical in every way but weight.

\section{Procedures}

Upon arriving, $S$ was seated and the brace taped to his right arm. The following instructions were read: "I am interested in the variables that affect the perception of weight. I am going to have you lift three pairs of cans, and after you lift the second can of each pair, I would like you to tell me if one of them felt heavier than the other or whether they both felt the same. You will be lifting the cans blindfolded, using this hook, with your arm taped to a metal strip and resting on the wooden frame. I will place the cans on the hook, so all you have to do is lift the cans and tell me how they feel to you. We will have a few practice trials before we begin in earnest. I am not interested in what these cans really weigh, or in what you think they probably weigh, but in just how they feel to you when you first pick them up."

After blindfolding $S$, there ensued a series of practice lifts using a dummy can until $E$ was satisfied that lifts were consistent and smooth. S was then presented with the three pairs of cans with an interval of $5 \mathrm{sec}$ between cans of a pair and greater than $20 \mathrm{sec}$ between pairs. On one pair of lifts there was no differency in initial angle, for one pair, a 30-deg difference, and for the other pair, a $60-\mathrm{deg}$ difference. The order of presentation of initial angles was systematically varied between Ss so that each angle difference occurred equally of ten in first, second, and third position. The absolute weight of the cans of a pair was changed for each pair, in a different order.

\section{RESULTS}

The results, shown in Fig. 2, reveal a dramatic shift toward judging the object lifted from a smaller initial angle as heavier. In fact, when one can was lifted from $60 \mathrm{deg}$ and the other from horizontal, the 60-deg can was never felt to be heavier and was judged to be equal only twice $(6.3 \%)$. When the difference in initial angle was $30 \mathrm{deg}$, the lesser angle lift was judged heavier on $66 \%$ of the lifts, equal on $16 \%$, and lighter on $18 \%$. When the two cans were hoisted from the same angle, the cans were judged to be equal almost half the time $(47 \%)$. In the condition where the initial angle was equal, the trials where the cans were judged to be unequal in weight were divided in half in Fig. 2 (indicated by asterisk). The shift away from judging the cans equal in weight was significant $(p<.01$, df $=2)$ when tested with the nonparametric Cochran Q (Siegel, 1956).

\section{DISCUSSION}

The results can be taken as support for the motor theory of comparative weight judgment, since there is no other reason to expect the difference in degree of initial arm bending to produce such startling changes in perception. The peripheral control of weight perception implicates proprioceptors in the lifting limb as the source of differential input. Since Ss were blindfolded throughout and the two cans of each pair were identical in weight, both vision and skin reception are rulled out. But from these data, it is impossible to determine which proprioceptors, or what combination of them, is responsible for the changed perception. The likely candidates are the muscle spindle afferents, joint receptors, and the golgi tendon organs, but when the arm is moved, all three receptor types are probably active (Granit, 1970). The presence of the arm brace greatly simplified the lever system by eliminating as nearly as possible the roles of the wrist and finger levers. Their combined role could be significant, since their initial angles do not necessarily change as the elbow bends.

The discovery that perception is tied to the effective lever length has broad application. It is a tenant of body mechanics that heavy loads should be carried close to the body (O'Connell \& Gardner, 1972). Likewise, in order to conserve force for speed, body levers (primarily arms and legs) are shortened by flexing distal joints. Indeed, as O'Connell and Gardner point out, "Skilled motor activity comes from making optimal use of body levers, decreasing or increasing their length as occasion 
demands, and timing the muscular control to act on them with only an optimal amount of force [p. 48]." Each of these lever adjustments may be accompanied by a change in the perceived heaviness, both of the limb itself and any external force. When we bend our elbows in order to move a tennis racket faster, the racket may feel lighter. Further, since heavy objects are almost always lifted through shorter effective levers than very light ones, the perceived difference in their weight is less than it would be if the lifting mechanics were the same, and is, in a sense, illusory.

The size of the effect found here suggests that theories of weight perception should take peripheral factors, particularly the biomechanics of lifting systems, into account.

\section{REFERENCES}

Davis, C. M. Mechanical advantage in the size-weight illusion.
Perception \& Psychophysics, 1973, 13, 238-240.

Granit, $\mathbf{R}$. The basis of motor control. New York: Academic Press, 1970

Müller, G. E., \& Schumann, F. Ueber die psychologischen Grundlagen der Vergleichung gehobener Gewichte. Archiv für die gesam te Physiologie, $1889,45,37-112$.

O'Connell, A. L., \& Gardner, E. B. Understanding the scientific bases of human movement. Baltimore: Williams \& Wilkins. 1972.

Siegel, S. Nonparametric statistics for the behavioral sciences. New York: McGraw-Hill, 1956.

\section{NOTE}

1. If there were no other biomechanical properties complicating the force diagram. the force required to support the object at an initial angle of $60 \mathrm{deg}$ would be half that required when the arm is horizontal since $E \times M A_{e}=R \times M A_{r}$, where MA is the moment arm of effort and $M A_{r}$ is the moment arm of resistance (produced by the can). But, as the elbow is bent, the moment arm of the muscle changes.

(Received for publication October 15, 1973; revision received February $8,1974$. ) 